\title{
INTEGRASI DESIGN FOR SIX SIGMA (DFSS) DAN TRIZ \\ PADA BISNIS JASA RENTAL SOUND SYSTEMUNTUK PENINGKATAN KEPUTUSAN PELANGGAN (Studi Kasus: UD. Cakra Music)
}

\author{
Rony Prabowo ${ }^{1}$, Erryx Setiawan ${ }^{2}$ \\ email: rony.prabowo@itats.ac.id, erryxsetiawan@gmail.com \\ Teknik Industri, Fakultas Teknologi Industri, Institut Adhi Tama Surabaya \\ Kampus ITATS Arief Rachman Hakim Surabaya 60117
}

\begin{abstract}
ABSTRAK
Banyak faktor yang harus diperhatikan dalam menjaga dan mewujudkan kepercayaan pelanggan terhadap bisnis jasa rental sound system, seperti etika dalam menawarkan, etika dalam melayani, menjaga kondisi fisik barang, menjaga performa barang, serta sumber daya manusia yang baik, yang mau menerima masukan dari konsumen pada saat acara, berbagai hal tersebut harus disusun dengan membuat standar operasional prosedur (SOP) dan harus dibuat sistem yang dapat meningkatkan pelayanan. Dengan adanya gap pada pelayan kualitas ini metode yang digunakan untuk menghilangkan gap tersebut adalah pendekatan Kaizen dengan memperhatikan konsep $5 \mathrm{~S}$ dan perbaikan manajerial serta DFSS yang berfokus pada DMADV yaitu (Define, Measure, Analyze dan Verify). Hasil yang diperoleh dari penelitian ini adalah terdapat 2 reject service yang paling dominan yang harus di perbaiki oleh UD. Cakra Music, yaitu harga sewa sound system dan cara kerja karyawan dan solusi yang harus dilakukan oleh perusahan UD. Cakra Music untuk mengatasi reject service yang paling dominan adalah dengan cara membuat harga paten dalam melakukan penjualan agar mudah mengatur keluar masuk biaya dan memberikan pelatihan pada karyawan tentang cara bersikap yang baik pada konsumen. Perusahaan perlu memperhatikan performa dari karyawan dan memberikan fasilitas kerja yang baik, seperti gaji yang pantas, memberikan baju seragam yang baik, memeberikan konsumsi yang baik, dan memeberikan tunjangan kerja yang baik.
\end{abstract}

Kata kunci: define, sound, kaizen, service, verify, gap

\section{PENDAHULUAN}

Salah satu bisnis jasa yang paling potensial dan sepanjang masa adalah rental sound system, dikatakan potensial dan sepanjang masa karena setiap acara membutuhkan sound system atau pengeras suara, mulai dari acara besar hingga acara kecil, sperti acara pernikahan, konser, birthday party, hingga seminar sekalipun, dari sini bisa dipastikan bahwa bisnis rental sound system adalah pilihan yang tepat jika memilih bisnis di bidang jasa, namun sound system yang dimaksudkan adalah sound yang berkualitas internasional sehingga bentuk fisiknya terlihat baik sehingga menunjang kualitas pelayanan dan konsumen merasa puas.

Bisnis jasa tidak bisa dibawa kemanapun hasilnya karena bukan berupa produk sehingga untuk kepuasan bisa diraskan langsung pada hari tersebut dan di tempat tersebut, sehingga untuk promosi ke khalayak luas sangat sulit karena hasil tidak bisa dibawa kemana-mana seenaknya (Feri \& Dominikus, 2010). Banyak faktor yang harus diperhatikan dalam menjaga dan mewujudkan kepercayaan pelanggan terhadap bisnis jasa rental sound system, seperti etika dalam menawarkan, etika dalam melayani, menjaga kondisi fisik barang, menjaga performa barang, serta sumber daya manusia yang baik, yang mau menerima masukan dari konsumen pada saat acara, berbagai hal tersebut harus disusun dengan membuat standar operasional prosedur (Cohen, 1995)

\section{METODE PENELITIAN}

\section{Konsep Six Sigma}

Six Sigma adalah konsep statistik yang mengukur suatu proses yang berkaitan dengan cacat pada level enam (six) sigma, hanya ada 3,4 cacat dari sejuta peluang dan Six Sigma pun merupakan falsafah manajemen yang berfokus untuk menghapus cacat dengan cara menekankan pemahaman, pengukuran dan perbaikan proses (Jaelani, 2012). Sedangkan Menurut (Saptadi, Arifin, \& Nugraha, 2010) Strategi six sigma merupakan metode sistematis yang menggunakan pengumpulan data dan analisis statistik untuk menentukan sumber-sumber variasi dan cara-cara untuk menghilangkannya (Poedjioetami \& Prabowo, 2015). 


\section{Konsep Design for Six Sigma}

Menurut (Anggraeni, Desrianty, \& Yuniar, 2013) Design For Six Sigma (DFSS) adalah sebuah metodologi manajemen bisnis proses yang berhubungan dengan Six Sigma tradisional. DFSS memiliki tujuan untuk menentukan kebutuhan dari konsumen dan bisnis serta mengarahkan kebutuhan tersebut ke dalam produk sehingga terciptalah suatu solusi (Aji \& Yuliawati, 2016). Selain itu DFSS juga cukup relevan dengan fase sintesis dari sistem, proses atau produk yang kompleks, khususnya dalam konteks pengembangan sistem yang belum pernah terjadi sebelumnya. Menurut (Prabowo \& Purwanto, 2016) DFSS ini juga sering dianalogikan dengan konsep DMADV (Define Measure Analyze Design Verify). Berbeda dengan DMAIC (Define Analyze Improve Control) sebagai Six Sigma tradisional, DFSS atau DMADV didesain untuk menghasilkan sebuah proses yang sebelumnya tidak ada atau ketika suatu proses yang sudah ada dianggap tidak memadai dan harus diganti.

Menurut (Trisna; Syamsul Ma'arif, 2012) tahapan umum pada DFSS adalah sebagai berikut : (1) Define yaitu dengan mendefinisikan tujuan proyek dan kebutuhan atau permintaan pelanggan maupun stakeholder; (2) Measure dengan mengukur dan menentukan kebutuhan dan spesifikasi pelanggan maupun stakeholder, pada tahapan ini juga diadakan perbandingan dengan kompetitor dan proses yang serupa dalam industri yang sama; (3) Analyze yaitu dengan menganalisa pilihan-pilihan yang ada dalam menjalankan proses untuk memenuhi kebutuhan pelanggan maupun stakeholder; (4) Design dengan cara menjabarkan rancangan proses dengan mendetail untuk memenuhi kebutuhan pelanggan; (5) Verify yaitu dengan memverifikasi performa perancangan dan kemampuan untuk memenuhi kebutuhan pelanggan maupun stakeholder.

\section{Tujuan dari Implementasi DFSS}

Pada saat tool Six Sigma pada umumnya berfungsi untuk memperbaiki proses agar berjalan dengan efisien dan sesuai fungsi, fungsi DFSS lebih kepada menentukan kebutuhan pelanggan, kebutuhan bisnis, dan memberikan apa yang dibutuhkan tersebut didalam produk atau proses yang diciptakan (Prabowo \& Purwanto, 2016). Perusahaan biasanya mengaplikasikan DFSS yang sesuai dengan bisnis, industri dan kebudayaan internal mereka (Batan Londen, n.d.) Ketika dikombinasikan, kedua metode tersebut akan membantu memenuhi kebutuhan pelanggan dan menciptakan sistem engineering yang dapat meningkatkan kualitas produk dan efektifitas proses bagi stakeholder (Kuswidiyanto, 2010).

\section{Metode TRIZ}

Menurut (Anggraeni et al., 2013). TRIZ merupakan kombinasi dari beberapa disiplin ilmu pengetahuan yaitu ilmu pengetahuan yang mempelajari alam (biologi, fisika, kimia, dan lain lain), ilmu pengetahuan yang mempelajari kebiasaan dan kehidupan manusia dalam bermasyarakat (psikologi dan sosiologi) dan ilmu pengetahuan yang mempelajari objek buatan (teknik rekayasa, disain, root cause, dan lain - lain).

Menurut (Chrisdiyanto, 2014) TRIZ sebagai salah satu teknik pemecahan masalah paling efektif. Agar sejalan dengan memperluas aplikasi TRIZ pada bidang jasa maka dibuat 40 prinsip inventif yang berguna untuk diakses.

Cara pertama dalam upaya mendapatkan masalah sebenarnya dan menemukan solusi yang terbaik dari masalah tersebut adalah dengan menemukan tradeoff di balik masalah tersebut karena di balik setiap permasalahan yang sulit terdapat kontradiksi/tradeoff (Schunk, 2009).. Menyelesaikan konflik merupakan alasan logis dibalik penemuan dan inovasi yang berhasil. Jika ingin memajukan teknologi, maka diperlukan pemahaman konflik. Jangan memperlakukan konflik tersebut sebagai "penyakit" yang harus dihilangkan, tetapi memperlakukannya sebagai petunjuk penting terhadap pencapaian solusi (Feri \& Dominikus, 2010).

\section{Langkah Penelitian}

Pada penelitian ini dapat diuraikan beberapa langkah penelitian dengan tahapan sebagai berikut:

1. Studi Pendahuluan

UD. Cakra Music, merupakan obyek penelitian yang dipilih oleh peneliti untuk menerapkan Design for Six Sigma karena proses untuk melayani costumer yang ada pada saat ini masih belum produktif dan juga belum efisien.

2. Studi Literatur

Tahap studi literatur ini dilakukan untuk memperoleh referensi dari teori terutama terkait lean manufacturing hal ini terkait dengan identifikasi pemborosan, Design for Six Sigma dengan siklus IDOV atupun DMADV yang nantinya digunakan sebagai pendekatan dalam melakukan perancangan proses dan desain perbaikan dari perumusan masalah yang telah dirumuskan pada tahap sebelumnya.

3. Define

Pada tahapan define ini tim DFSS harus mampu merancang kebutuhan konsumen, stakeholder dan konsumen melalui analisis situasi sehingga perancangan proses sesuai dengan sumber daya yang dimiliki oleh perusahaan. 
4. Measure

Pada tahap ini, akan dilakukan pengukuran pengukuran pada proses atau kinerja proses yang berlangsung.

5. Analyze

Pada tahapan analisis ini karakteristik proses harus dianalisa secara lengkap dan detail yang meliputi analisis kunci,

6. Design

Desain terkait dengan perancangan stasiun kerja, tata letak fasilitas serta desain untuk rekayasa spesifikasi proses. Semua parameter proses harus dapat diidentifikasi dan dilakukan analisa kegagalan proses untuk menentukan potensi risiko serta ketahanan proses dalam ukuran waktu tertentu.

7. Verify

Tahap ini dimaksudkan untuk melihat adanya perbaikan hasil atau tidak sebelum dengan sesudah perbaikan dengan uji selisih proporsi/uji hipotesis setelah dilakukan analisis kapabilitas proses pasca implementasi.

8. Kesimpulan dan Saran

Bab ini merupakan bab penutup yang berisi mengenai kesimpulan dari hasil analisis yang telah dilakukan dan juga berisi mengenai saran-saran bagi pengembangan hasil penelitian selanjutnya.

\section{HASIL DAN PEMBAHASAN}

\section{Define}

(a) Penentuan CTQ

Dari hasil analisa permasalahan dan dampaknya terdapat 9 permasalahan utama yang dialami oleh perusahaan dan masing masing memiliki dampak negatif yang cukup signifikan bagi konsumen.

Tabel 1. Permasalahan yang dialamai UD. Cakra Music beserta dampaknya

\begin{tabular}{|c|c|c|}
\hline No. & Permasalahan & Dampak yang timbul \\
\hline \multirow[t]{2}{*}{1.} & \multirow{2}{*}{$\begin{array}{l}\text { Merk sound system yang } \\
\text { tidak sama atau tidak } \\
\text { seseri }\end{array}$} & Suara yang di hasilkan di setiap sudut berbeda \\
\hline & & Bentuk sound yang tidak sama sehingga kurang menarik \\
\hline \multirow[t]{2}{*}{2.} & \multirow{2}{*}{$\begin{array}{l}\text { Karyawan tidak memiliki } \\
\text { rasa empati }\end{array}$} & Terjadinya miskomunikasi \\
\hline & & Tidak mampunya menimbulkan kesan yang baik pada client \\
\hline \multirow[t]{2}{*}{3.} & \multirow{2}{*}{$\begin{array}{l}\text { Kurangnya pengetahuan } \\
\text { tentang kelistrikan dari } \\
\text { karyawan }\end{array}$} & karena tidak seimbangannya pembagian listrik \\
\hline & & Rawan terjadinya kecacatan dalam pelayanan \\
\hline \multirow[t]{2}{*}{4.} & \multirow{2}{*}{$\begin{array}{l}\text { Kesiapan karyawan dalam } \\
\text { bekerja }\end{array}$} & Tidak maunya client berkomunikasi dengan karyawan \\
\hline & & Penampilan karyawan yang kurang rapi \\
\hline \multirow[t]{2}{*}{5.} & \multirow{2}{*}{$\begin{array}{l}\text { Kurangnya pengetahuan } \\
\text { tentang elektronika dari } \\
\text { karyawan }\end{array}$} & $\begin{array}{l}\text { Tidak mampunya karyawan dalam memperbaiki equipment } \\
\text { yang rusak }\end{array}$ \\
\hline & & $\begin{array}{l}\text { Tidak mampunya karyawan memperlakukan equipment } \\
\text { dengan baik }\end{array}$ \\
\hline \multirow[t]{2}{*}{6.} & \multirow[t]{2}{*}{$\begin{array}{l}\text { Kecepatan loading barang } \\
\text { yang tidak bisa dipastikan }\end{array}$} & $\begin{array}{l}\text { Tidak mampu memberikan janji kepada client tentang } \\
\text { ketepatan waktu menyelesaikan loading }\end{array}$ \\
\hline & & $\begin{array}{l}\text { Sulit mengatur waktu loading ketika mendapatkan } 2 \text { event } \\
\text { yang bersamaan }\end{array}$ \\
\hline \multirow[t]{2}{*}{7.} & \multirow{2}{*}{$\begin{array}{l}\text { Persaingan yang ketat dan } \\
\text { seringkali merendahkan } \\
\text { harga jual }\end{array}$} & Harga yang semakin jatuh \\
\hline & & Rendahnya nilai bisnis soundsytem \\
\hline \multirow[t]{2}{*}{8.} & \multirow{2}{*}{$\begin{array}{l}\text { Harga jual yang tidak } \\
\text { selalu pasti }\end{array}$} & Gaji karyawan yang ikut fluktuatif \\
\hline & & Margin yanng tidak dapat pasti \\
\hline \multirow[t]{2}{*}{9.} & \multirow{2}{*}{$\begin{array}{l}\text { Sound system yang } \\
\text { merupakan sound merk } \\
\text { Cina }\end{array}$} & Suara yang sangat tajam di telinga \\
\hline & & $\begin{array}{l}\text { Jika di saingkan dengan produk merk lain misal dari barat } \\
\text { peluang untuk menang sangat kecil }\end{array}$ \\
\hline
\end{tabular}

(b) Penentuan VOC

Diagram ini membagi spesifikasi dari pelanggan menjadi tiga jenis, harus ada (must be), Kemampuan (Performance) dan pemuas (delighter), dan membandingkan dengan tingkat keberadaan suatu spesifikasi. 
Tabel 2. VOC Pada UD. Cakra Music

\begin{tabular}{|c|c|}
\hline Komplain & Keinginan \\
\hline $\begin{array}{c}\text { Cara komunikasi karyawan yang kurang } \\
\text { baik dengan client }\end{array}$ & Dilayani dengan sopan dan cara komunikasi \\
yang baik
\end{tabular}

Analisa SIPOC (Supplier - Input - Process - Output - Customer)

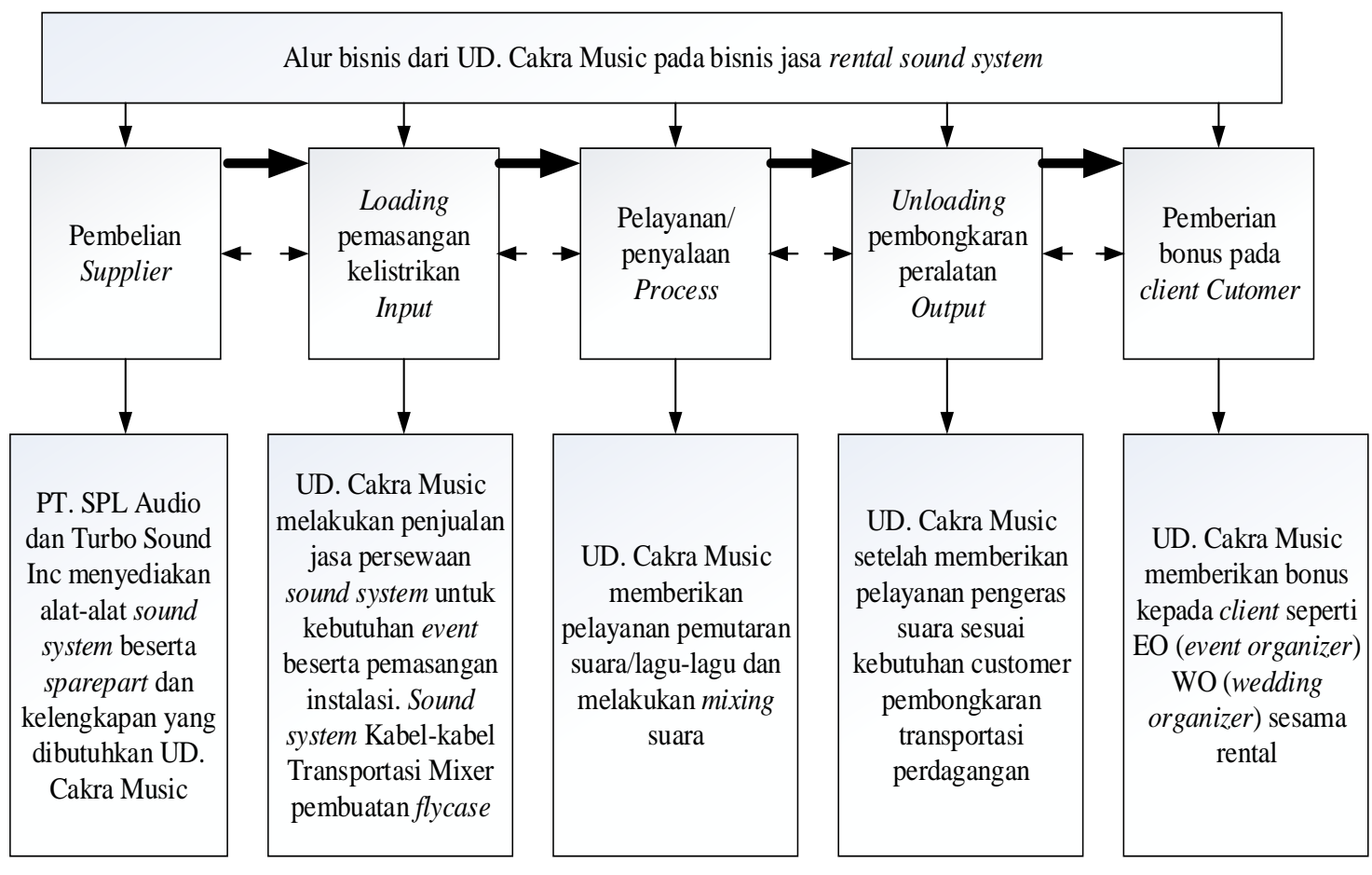

Keterangan: $=\longrightarrow$ Aliran Jasa; $\rightarrow=$ aliran pembiayaan ekternal $\rightarrow \longrightarrow-\rightarrow=$ aliran pembiayaan internal

Gambar 2. Aliran SIPOC

\section{Measure}

(a) Analisa Pesaing

Persaingan yang sangat ketat membuat UD.

Cakra Music harus terus meningkatkan pelayanan, agar customer tidak pergi ke rental sound system lain, dua pesaing yang dianggap perlu diperhatikan agar UD. Cakra Music tidak kehilangan customer adalah UD. Tata Suara dan CV. Praktika Sound, kedua perusahaan tersebut beberapa kelebihan dan kekurangan antara lain adalah : 
Tabel 3. Analisa Kekurangan Dan Kelebihan Kondisi Pesaing Dari UD. Cakra Music

\begin{tabular}{|c|c|c|c|c|}
\hline \multirow{2}{*}{ No. } & \multicolumn{2}{|c|}{ UD. Tata Suara } & \multicolumn{2}{|c|}{ CV. Praktika Sound } \\
\hline & Kekurangan & Kelebihan & Kekurangan & Kelebihan \\
\hline 1. & $\begin{array}{l}\text { Jumlah sound } \\
\text { yang sedikit }\end{array}$ & $\begin{array}{c}\text { Owner memiliki banyak } \\
\text { kenalan di kalangan anak } \\
\text { band }\end{array}$ & Sound tipe lama & $\begin{array}{l}\text { Sound dengan } \\
\text { kualitas standart } \\
\text { Amerika }\end{array}$ \\
\hline 2. & $\begin{array}{l}\text { Crew dengan } \\
\text { pengetahuan } \\
\text { tentang sound } \\
\text { yang kurang }\end{array}$ & $\begin{array}{c}\text { Penampilan crew yang } \\
\text { sangat baik atau keren- } \\
\text { keren }\end{array}$ & $\begin{array}{l}\text { Penampilan barang } \\
\text { yang kurang baik }\end{array}$ & $\begin{array}{l}\text { Crew memiliki fisik } \\
\text { yang tangguh dan } \\
\text { terlatih }\end{array}$ \\
\hline 3. & $\begin{array}{l}\text { Crew dengan fisik } \\
\text { yang kurang kuat }\end{array}$ & $\begin{array}{l}\text { Etika crew yang baik dan } \\
\text { sopan }\end{array}$ & $\begin{array}{l}\text { Penampilan crew } \\
\text { yang kurang rapi }\end{array}$ & $\begin{array}{l}\text { Barang pendukung } \\
\text { sound system yang } \\
\text { sangat lengkap }\end{array}$ \\
\hline 4. & $\begin{array}{c}\text { Armada } \\
\text { transportasi yang } \\
\text { sedikit }\end{array}$ & $\begin{array}{l}\text { Pandai mengatur jadwal } \\
\text { loading karena jumlah } \\
\text { sound sedikit }\end{array}$ & $\begin{array}{l}\text { Sulit mengatur } \\
\text { jadwal loading }\end{array}$ & $\begin{array}{l}\text { Memiliki armada } \\
\text { transportasi yang } \\
\text { banyak }\end{array}$ \\
\hline 5. & $\begin{array}{c}\text { Sound system } \\
\text { dengan beberapa } \\
\text { merk }\end{array}$ & Barang yang bersih-bersih & $\begin{array}{c}\text { Armada yang kurang } \\
\text { prima }\end{array}$ & $\begin{array}{l}\text { Memiliki crew yang } \\
\text { cukup banyak }\end{array}$ \\
\hline
\end{tabular}

(b) Pareto Diagram

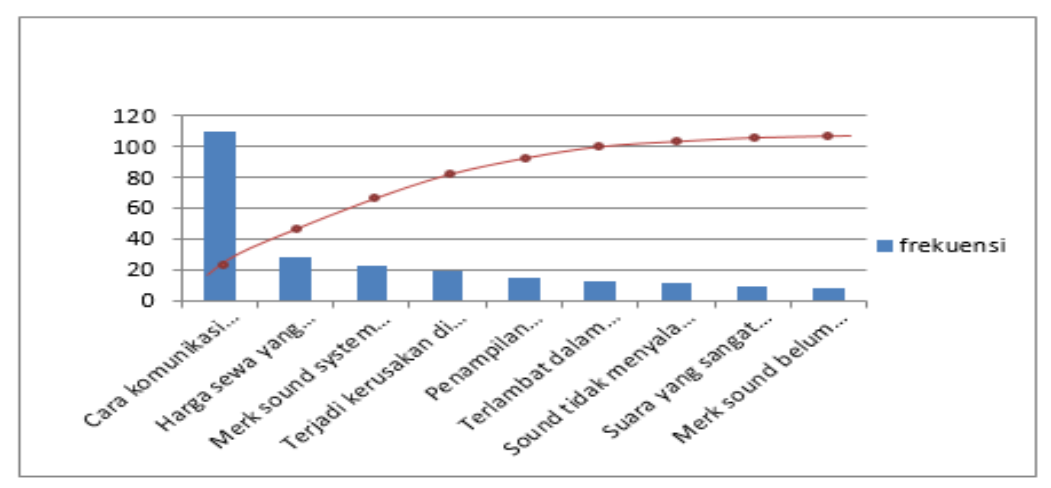

Gambar 3. Pareto Diagram

Tabel 4. Perhitungan Tingkat Kegagalan Pelayanan

\begin{tabular}{|c|c|c|c|c|}
\hline No. & Proses & Reject Service & Frequncy & $\begin{array}{l}\text { Percentage } \\
\text { from total }\end{array}$ \\
\hline 1. & $\begin{array}{l}\text { Pembelian/pengadaan barang } \\
\text { yang tidak bersamaan }\end{array}$ & $\begin{array}{l}\text { Merk sound system yang tidak } \\
\text { sama atau tidak seseri }\end{array}$ & 23 & 9,58 \\
\hline 2. & $\begin{array}{l}\text { Karyawan tidak memiliki rasa } \\
\text { empati }\end{array}$ & $\begin{array}{l}\text { Cara komunikasi } \begin{array}{c}\text { karyawan } \\
\text { yang kurang baik dengan client }\end{array} \\
\end{array}$ & 110 & 45,83 \\
\hline 3. & \begin{tabular}{lr} 
Kurangnya & \multicolumn{2}{c}{ pengetahuan } \\
tentang kelistrikan dari \\
karyawan
\end{tabular} & $\begin{array}{l}\text { Sound tidak menyala } \begin{array}{r}\text { secara } \\
\text { maksimal sesuai } \\
\text { fungsinya }\end{array} \\
\end{array}$ & 12 & 5 \\
\hline 4. & $\begin{array}{l}\text { Persiapan karyawan dalam } \\
\text { bekerja }\end{array}$ & $\begin{array}{l}\text { Penampilan karyawan yang } \\
\text { kurang rapi }\end{array}$ & 15 & 6,25 \\
\hline 5. & $\begin{array}{l}\text { Kurangnya pengetahuan } \\
\text { tentang elektronika dari } \\
\text { karyawan }\end{array}$ & $\begin{array}{l}\text { Terjadi kerusakan di tengah - } \\
\text { tengah acara dan tidak mampu } \\
\text { tertangani }\end{array}$ & 20 & 8,33 \\
\hline 6. & $\begin{array}{l}\text { Kecepatan loading barang } \\
\text { yang tidak bisa dipastikan }\end{array}$ & $\begin{array}{l}\text { Terlambat dalam persiapan } \\
\text { barang }\end{array}$ & 13 & 5,41 \\
\hline 7. & Karakter sound produk Asia & $\begin{array}{l}\text { Suara yang sangat tajam di } \\
\text { telinga }\end{array}$ & 10 & 4,16 \\
\hline 8. & Penentuan harga sewa & $\begin{array}{l}\text { Harga sewa yang tidak selalu } \\
\text { pasti }\end{array}$ & 29 & 12,08 \\
\hline 9. & $\begin{array}{l}\text { Sound } \quad \text { system yang } \\
\text { merupakan sound merk cina }\end{array}$ & $\begin{array}{l}\text { Merk sound belum memiliki } \\
\text { branch image yang baik }\end{array}$ & 8 & 3,33 \\
\hline
\end{tabular}


Tabel 5. Fault Tree Analysis Untuk Harga Sewa Sound System

\begin{tabular}{|c|c|c|c|c|c|c|c|c|}
\hline \multirow{2}{*}{ No. } & \multirow{2}{*}{ Gate } & \multirow{2}{*}{ Event } & \multirow{2}{*}{ Penyebab } & \multicolumn{4}{|c|}{ Ranking } & \multirow{2}{*}{ Total } \\
\hline & & & & 1 & 2 & 3 & 4 & \\
\hline 1. & $\mathrm{C}$ & B1 & Tidak mampu memberi gaji tetap pada karyawan & 0,4 & 0,5 & 0,5 & 0,6 & 0,5 \\
\hline 2. & $\mathrm{D}$ & B2 & Sulit mengatur keluar masuk cost & 0,6 & 0,6 & 0,7 & 0,5 & 0,6 \\
\hline \multirow[b]{2}{*}{3.} & \multirow[b]{2}{*}{$\mathrm{E}$} & B3 & Karakter sound produk Asia & 0,6 & 0,4 & 0,5 & 0,3 & 0,45 \\
\hline & & B4 & $\begin{array}{l}\text { Kurangnya kedekatan dengan client, karena baru } \\
\text { pertama kali menggunakan jasa }\end{array}$ & 0,6 & 0,6 & 0,5 & 0,5 & 0,55 \\
\hline \multirow[t]{2}{*}{4.} & \multirow[t]{2}{*}{$\mathrm{F}$} & B5 & $\begin{array}{l}\text { Tidak memiliki kemampuan membaca keinginan } \\
\text { client }\end{array}$ & 0,3 & 0,4 & 0,3 & 0,4 & 0,35 \\
\hline & & B6 & Sound system yang merupakan sound merk cina & 0,6 & 0,5 & 0,5 & 0,6 & 0,55 \\
\hline 5. & G & B7 & $\begin{array}{l}\text { Kurangnya pengetahuan tentang elektronika dari } \\
\text { karyawan }\end{array}$ & 0,5 & 0,5 & 0,5 & 0,4 & 0,48 \\
\hline 6. & $\mathrm{H}$ & B8 & $\begin{array}{llll}\begin{array}{l}\text { Kurangnya } \\
\text { karyawan }\end{array} & \text { pengetahuan tentang listrik dari } \\
\end{array}$ & 0,6 & 0,5 & 0,6 & 0,6 & 0,58 \\
\hline
\end{tabular}

\section{Analyze}

(a) Pembuatan FMEA (Failure Mode Effect Analisys)

Tabel 6. FMEA pelayanan UD. Cakra Music

\begin{tabular}{|c|c|c|c|c|c|c|c|c|}
\hline Proses & $\begin{array}{l}\text { Metode Kegagalan } \\
\text { Potensial }\end{array}$ & Akibat Potensial & 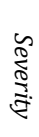 & $\begin{array}{l}\text { Penyebab } \\
\text { Potensial dari } \\
\text { Kegagalan }\end{array}$ & 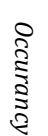 & Perencanaan Deteksi & 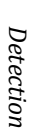 & $\begin{array}{c}\text { Risk } \\
\text { Priority } \\
\text { Number }\end{array}$ \\
\hline $\begin{array}{l}\text { Pembelian/pengada } \\
\text { an barang yang } \\
\text { tidak bersamaan }\end{array}$ & $\begin{array}{l}\text { - Ketidakpuasan } \\
\text { client tentang } \\
\text { bentuk yang } \\
\text { kurang menarik } \\
\text { - Kehilangan client }\end{array}$ & $\begin{array}{l}\text { - Suara yang dihasilkan } \\
\text { di setiap sudut } \\
\text { berbeda } \\
\text { - Bentuk sound yang } \\
\text { tidak sama sehingga } \\
\text { kurang menarik } \\
\end{array}$ & 5 & $\begin{array}{l}\text { Merek sound } \\
\text { system yang tidak } \\
\text { sama atau tidak } \\
\text { sesuai }\end{array}$ & 8 & $\begin{array}{l}\text { Memeriksa merk sound yang } \\
\text { terbanyak yang dimiliki, } \\
\text { kemudian melengkapi } \\
\text { menjadi system dengan merek } \\
\text { sound yang sama dan menjual } \\
\text { merek yang tidak sama }\end{array}$ & 9 & 360 \\
\hline $\begin{array}{l}\text { Sound system yang } \\
\text { merupakan sound } \\
\text { merek Cina }\end{array}$ & $\begin{array}{l}\text { Client berpaling } \\
\text { dan memilih sound } \\
\text { merek lain }\end{array}$ & $\begin{array}{l}\text { Client meragukan } \\
\text { kualitas equipment }\end{array}$ & 6 & $\begin{array}{l}\text { Merek sound } \\
\text { belum memiliki } \\
\text { branch image } \\
\text { yang baik }\end{array}$ & 5 & $\begin{array}{l}\text { Mengganti sound system } \\
\text { dengan merek Eropa }\end{array}$ & 4 & 120 \\
\hline $\begin{array}{l}\text { Kurangnya } \\
\text { pengetahuan } \\
\text { tentang kelistrikan } \\
\text { dan karyawan }\end{array}$ & $\begin{array}{l}\text { Mengganti } \\
\text { equipment yang } \\
\text { rusak }\end{array}$ & $\begin{array}{l}\text { Tidak seimbangnya } \\
\text { pembagian listrik }\end{array}$ & 4 & $\begin{array}{l}\text { Sound tidak } \\
\text { menyala secara } \\
\text { maksimal }\end{array}$ & 8 & $\begin{array}{l}\text { Memberikan pengetahu an } \\
\text { atau pelatihan tentang } \\
\text { kelistrikan }\end{array}$ & 5 & 160 \\
\hline $\begin{array}{l}\text { Persiapan } \\
\text { karyawan dalam } \\
\text { bekerja }\end{array}$ & $\begin{array}{l}\text { Kurangnya } \\
\text { kerjasama dengan } \\
\text { client }\end{array}$ & $\begin{array}{l}\text { Tidak bersedianya } \\
\text { client berkomunikasi } \\
\text { dengan karyawan }\end{array}$ & 6 & $\begin{array}{l}\text { Penampilan } \\
\text { karyawan yang } \\
\text { kurang rapi } \\
\end{array}$ & 4 & Memberikan pengertian pada & 4 & 96 \\
\hline $\begin{array}{l}\text { Kurangnya } \\
\text { pengetahuan } \\
\text { tentang } \\
\text { keletrikalan dari } \\
\text { karyawan }\end{array}$ & $\begin{array}{l}\text { Terkena sangsi } \\
\text { penalti } \\
\text { pembayaran }\end{array}$ & $\begin{array}{l}\text { Tidak mempunyai } \\
\text { karyawan dalam } \\
\text { memperbaiki } \\
\text { equipment yang rusak }\end{array}$ & 5 & $\begin{array}{l}\text { Terjadi } \\
\text { kerusakan di } \\
\text { tengah-tengah } \\
\text { acara dan tidak } \\
\text { mampu } \\
\text { tertangani } \\
\end{array}$ & 7 & $\begin{array}{l}\text { Memberikan pelatihan khusus } \\
\text { pada karyawan tentang } \\
\text { bagaimana memperbaiki } \\
\text { peralatan sound system }\end{array}$ & 6 & 210 \\
\hline $\begin{array}{l}\text { Loading dan } \\
\text { unloading }\end{array}$ & $\begin{array}{l}\text { Mengganggu } \\
\text { jadwal event }\end{array}$ & $\begin{array}{l}\text { Tidak mempunyai } \\
\text { memberikan janji } \\
\text { kepada client tentang } \\
\text { ketepatan waktu } \\
\text { menyelesaikan loading }\end{array}$ & 8 & $\begin{array}{l}\text { Terlambat dalam } \\
\text { persiapan barang }\end{array}$ & 5 & $\begin{array}{l}\text { Memberi pengertian kepada } \\
\text { karyawan tentang } \\
\text { mempersiapkan fisik yang } \\
\text { baik sebelum bekerja sehingga } \\
\text { kinerjanya menjadi prima }\end{array}$ & 3 & 120 \\
\hline $\begin{array}{l}\text { Karakter sound } \\
\text { produk Asia }\end{array}$ & $\begin{array}{l}\text { Sulit mengatur } \\
\text { letak }\end{array}$ & $\begin{array}{l}\text { Client tidak nyaman } \\
\text { apabila berada dekat } \\
\text { dengan sound }\end{array}$ & 7 & $\begin{array}{l}\text { Suara yang } \\
\text { sangat tajam di } \\
\text { telinga }\end{array}$ & 6 & $\begin{array}{l}\text { Mengatur volume dan sound } \\
\text { system }\end{array}$ & 3 & 126 \\
\hline $\begin{array}{l}\text { Penentuan harga } \\
\text { sewa }\end{array}$ & $\begin{array}{l}\text { Sulit memperoleh } \\
\text { karyawan tetap }\end{array}$ & $\begin{array}{l}\text { Gaji karyawan } \\
\text { fluktuatif }\end{array}$ & 9 & $\begin{array}{l}\text { Marjin yang } \\
\text { diperoleh } \\
\text { fluktuatif }\end{array}$ & 8 & $\begin{array}{l}\text { Menentukan harga paket } \\
\text { untuk setiap paket yang } \\
\text { disewakan }\end{array}$ & 7 & 504 \\
\hline $\begin{array}{l}\text { Karyawan tidak } \\
\text { memiliki rasa } \\
\text { empati }\end{array}$ & $\begin{array}{l}\text { Client tidak menola } \\
\text { untuk dilayani oleh } \\
\text { karyawan tertentu }\end{array}$ & $\begin{array}{l}\text { - Terjadinya } \\
\text { miskomunikasi } \\
\text { - Tidak dapat } \\
\text { memuncul } \\
\text { kan kesan yang baik } \\
\text { pada client } \\
\end{array}$ & 8 & $\begin{array}{l}\text { Kurangnya } \\
\text { interaksi antara } \\
\text { karyawan } \\
\text { dengan client }\end{array}$ & 7 & $\begin{array}{l}\text { Memberikan pelatihan public } \\
\text { speaking pada karyawan }\end{array}$ & 9 & 504 \\
\hline Setting equipment & $\begin{array}{l}\text { Penyelesaian tidak } \\
\text { sesuai dengan } \\
\text { harapan client }\end{array}$ & $\begin{array}{l}\text { Waktu setting yangn } \\
\text { lama }\end{array}$ & 5 & $\begin{array}{l}\text { Kondisi venue } \\
\text { yang sulit }\end{array}$ & 6 & $\begin{array}{l}\text { Keberangkatan ke lokasi lebih } \\
\text { awal }\end{array}$ & 5 & 150 \\
\hline
\end{tabular}




\section{(b) Penyusunan TRIZ (Theory of Inventive Problem Solving) Engineering Parameter}

Tabel 7. Engineering Parameter

\begin{tabular}{|c|c|c|c|c|c|}
\hline No & Daftar & Keterangan & No & Daftar & Keterangan \\
\hline 1. & $\begin{array}{l}\text { Weight of moving } \\
\text { object }\end{array}$ & $\begin{array}{l}\text { Massa equipment dipengaruhi elemen yang } \\
\text { menyusun produk tersebut }\end{array}$ & 21. & Power & $\begin{array}{l}\text { equipment terbaik membutuhkan listrik } \\
\text { cukup tinggi }\end{array}$ \\
\hline 2. & $\begin{array}{l}\text { Weight stationary } \\
\text { object }\end{array}$ & $\begin{array}{l}\text { Massa equipment dipengaruhi berat } \\
\text { equipment, panjang dan lebar mesin }\end{array}$ & 22. & Loss of energy & $\begin{array}{l}\text { Listrik terbuang karena pembagian listrik } \\
\text { seimbang atau mengalami kebocoran }\end{array}$ \\
\hline 3. & $\begin{array}{l}\text { Length of moving } \\
\text { object }\end{array}$ & $\begin{array}{l}\text { Dimensi equipment sama hanya ukuran } \\
\text { panjang lebar dan spesifikasi yang } \\
\text { membedakan }\end{array}$ & 23. & $\begin{array}{l}\text { Loss of } \\
\text { substance }\end{array}$ & $\begin{array}{l}\text { Sperpart equipment tidak berfungsi } \\
\text { dengan baik dikarenakan kurangnya } \\
\text { pengetahuan tentang listrik dari karyawan }\end{array}$ \\
\hline 4. & $\begin{array}{l}\text { Length of stationary } \\
\text { object }\end{array}$ & $\begin{array}{l}\text { Dimensi equipment berbeda sesuai jenis dan } \\
\text { fungsinya }\end{array}$ & 24. & $\begin{array}{l}\text { Loss of } \\
\text { information }\end{array}$ & $\begin{array}{l}\text { Tidak memiliki kemampuan membaca } \\
\text { keinginan client }\end{array}$ \\
\hline 5. & Area Moving object & Gudang cukup sempit & 25. & Loss of time & $\begin{array}{l}\text { equipment yang tidak sesuai spesifikasi } \\
\text { dapat beresiko mempengaruhi kualitas } \\
\text { jasa. }\end{array}$ \\
\hline 6. & Area stationary & $\begin{array}{l}\text { Memiliki fleksibelitas bergerak apabila } \\
\text { mengalami perbaikan dalam perpindahan }\end{array}$ & 26. & $\begin{array}{l}\text { Quantity of } \\
\text { substance / the } \\
\text { matter }\end{array}$ & $\begin{array}{l}\text { Harga jual yag tidak pasti dan banyak } \\
\text { permasalahan yang tidak terduga } \\
\text { mengakibatkan sulit mengatur keluar } \\
\text { masuk cost. }\end{array}$ \\
\hline 7. & $\begin{array}{l}\text { Volume moving } \\
\text { Object }\end{array}$ & $\begin{array}{l}\text { equipment mudah untuk dipindahkan, } \\
\text { Karyawan tidak memiliki rasa empati }\end{array}$ & 27. & Relyability & $\begin{array}{l}\text { Kurangnya kedekatan dengan client, } \\
\text { karena baru pertama kali menggunakan } \\
\text { jasa, Kondisi equipment dapat } \\
\text { mempengaruhi suara yang akan dihasilkan } \\
\text { dan kerjasama antar karyawan akan } \\
\text { berdampak positiv. }\end{array}$ \\
\hline 8. & Volume stationary & $\begin{array}{l}\text { Kapasitas sound } 60.000 \text { watt line array beserta } \\
\text { perlengkapan pendukung }\end{array}$ & 28. & $\begin{array}{l}\text { measurement } \\
\text { accurance }\end{array}$ & $\begin{array}{l}\text { Pengukuran kualitas pelayanan dengan } \\
\text { memberikan toleransi }\end{array}$ \\
\hline 9. & Speed & $\begin{array}{l}\text { Kecepatan loading barang yang tidak bisa } \\
\text { dipastikan, Rata - rata waktu dalam } \\
\text { melakukan persiapan } 30 \text { menit/event }\end{array}$ & 29. & $\begin{array}{l}\text { Manufacturing } \\
\text { precision }\end{array}$ & $\begin{array}{l}\text { Kurangnya pengetahuan tentang } \\
\text { elektronika dari karyawan }\end{array}$ \\
\hline 10. & Force & $\begin{array}{l}\text { Pengaturan kelistrikan dan perlakuan sesuai } \\
\text { kapasitas watt perlu diperhatikan }\end{array}$ & 30. & $\begin{array}{l}\text { Object- } \\
\text { generated } \\
\text { harmful } \\
\text { lfactors }\end{array}$ & $\begin{array}{l}\text { Kualitas kabel-kabel pendukung yang jelek } \\
\text { sehingga suara tidak halus }\end{array}$ \\
\hline 11. & Stress or pressure & $\begin{array}{l}\text { Tidak mampu memberi gaji tetap pada } \\
\text { karyawan }\end{array}$ & 31. & $\begin{array}{l}\text { Object- } \\
\text { generated } \\
\text { harmfull } \\
\text { factors }\end{array}$ & $\begin{array}{l}\text { Banyak equipment rusak karena dalam } \\
\text { proses loading dan unloading karyawan } \\
\text { tidak memperlakukan equipment dengan } \\
\text { baik }\end{array}$ \\
\hline 12. & Shape & $\begin{array}{l}\text { Bentuk pada setiap equipment sama hanya } \\
\text { ukuran dan spesifikasi yang membedakan. }\end{array}$ & 32. & $\begin{array}{l}\text { Ease of } \\
\text { manufacture }\end{array}$ & $\begin{array}{l}\text { Minim fasilitas diruang gudang dan } \\
\text { suasana gudang yang panas dan sempit. }\end{array}$ \\
\hline 13. & $\begin{array}{l}\text { Stability of the } \\
\text { object,scompotion }\end{array}$ & $\begin{array}{l}\text { equipment akan mampu memepertahankan } \\
\text { elemen penyesun ketika dilakukan } \\
\text { penyimpanan dengan baik }\end{array}$ & 33. & $\begin{array}{l}\text { Ease Of } \\
\text { operation }\end{array}$ & $\begin{array}{l}\text { Pembelian/ pengadaan barang yang tidak } \\
\text { bersamaan menyebabkan Sound tidak satu } \\
\text { merk, dan Suara yang dihasilkan disetiap } \\
\text { sudutpun tentu berbeda-beda }\end{array}$ \\
\hline 14. & Strenght & $\begin{array}{l}\text { Dipengaruhi kondisi lingkungan dan berat } \\
\text { beban serta kesiapan karyawan dalam bekerja }\end{array}$ & 34. & Ease of repair & $\begin{array}{l}\text { Membutuhkan waktu dan biaya dalam } \\
\text { reparasi produk }\end{array}$ \\
\hline 15. & $\begin{array}{l}\text { Duration action by } \\
\text { moving object }\end{array}$ & $\begin{array}{l}\text { Tingkat depresiasi equipment sound dengan } \\
\text { karakter asia rentan mengalami kerusakan } \\
\text { apabila digunakan antara 5-10 tahun }\end{array}$ & 35. & $\begin{array}{l}\text { Adaptability or } \\
\text { versatility }\end{array}$ & $\begin{array}{l}\text { Dalam kondisi suhu yang stabil equipment } \\
\text { mampu bertahan lama }\end{array}$ \\
\hline 16. & $\begin{array}{l}\text { Duration action by } \\
\text { stationary object }\end{array}$ & $\begin{array}{l}\text { Sound system yang merupakan sound merk cina } \\
\text { memiliki ketahanan hanya sekitar } 10 \text { tahun } \\
\text { apabila di rawat dengan baik }\end{array}$ & 36. & $\begin{array}{l}\text { Device } \\
\text { complexity }\end{array}$ & $\begin{array}{l}\text { Target kualitas tidak sesuai dengan } \\
\text { pelayanan yang baik dan sopan dari } \\
\text { karyawan }\end{array}$ \\
\hline 17. & Temperature & $\begin{array}{l}\text { Kemampuan menyerap panas sesuai dengan } \\
\text { suhu kamar }\left( \pm 30^{\circ}\right)\end{array}$ & 37. & $\begin{array}{l}\text { Difficulty } \\
\text { detecting and } \\
\text { measuring }\end{array}$ & $\begin{array}{l}\text { Kesulitan dalam mendeteksi permasalahan } \\
\text { pada equipment yang jenis dan masalah } \\
\text { yang berbeda-beda }\end{array}$ \\
\hline 18. & $\begin{array}{l}\text { Illumination } \\
\text { intensive/brightness }\end{array}$ & $\begin{array}{l}\text { Intensitas cahaya di dalam ruangan } \\
\text { menggunakan bantuan penerangan. }\end{array}$ & 38. & $\begin{array}{l}\text { Extent of } \\
\text { automation }\end{array}$ & $\begin{array}{l}\text { Jumlah karyawan sebagai soundmain } 3 \\
\text { crew } 6 \text {, driver } 2 \text { yang mampu melayani } 3 \\
\text { event dalam sehari. }\end{array}$ \\
\hline 19. & $\begin{array}{l}\text { Use energy by } \\
\text { moving object }\end{array}$ & $\begin{array}{l}\text { equipment yang memiliki konsumsi energi } \\
\text { tinggi }\end{array}$ & 39. & Productivity & Output dan Input tidak seimbang \\
\hline
\end{tabular}


Tabel 8. Inventive Principles

\begin{tabular}{|c|c|c|}
\hline No & Daftar & Keterangan \\
\hline 1. & Segmentation & $\begin{array}{l}\text { Memetakan atau mengkategorikan konsumen } \\
\text { seperti pelajar, EO, WO, dan Corporate }\end{array}$ \\
\hline 2. & Separation & $\begin{array}{l}\text { Pemisahan atau pembedaan pelayanan pada } \\
\text { setiap konsumen yang telah di kategorikan }\end{array}$ \\
\hline 3. & Local quality & $\begin{array}{l}\text { Timbulnya perbedaan kualitas pelayanan yang } \\
\text { diinginkan oleh konsumen pada setiap daerah } \\
\text { antara konsumen lokal daerah dan interlokal } \\
\text { daerah }\end{array}$ \\
\hline 4. & Asymmetry & $\begin{array}{l}\text { Perubahan dalam segala hal pokok karena } \\
\text { diakibatkan oleh keinginan konsumen }\end{array}$ \\
\hline 5. & Merging & $\begin{array}{l}\text { Menggabungkan atau mengkombinasikan } \\
\text { segala hal yang dapat meningkatkan pelayanan } \\
\text { perusahaan }\end{array}$ \\
\hline 6. & Multyfunctionality & $\begin{array}{l}\text { Mampu memfungsikan peralatan sesuai } \\
\text { kondisi, misal lokasi yang besar maupun kecil, } \\
\text { ataupun sound system yang digantung dengan } \\
\text { yang di taruh bawah }\end{array}$ \\
\hline 7. & "Nested doll" & $\begin{array}{l}\text { Menangani permasalahan yang terlalu lama } \\
\text { tidak diselesaikan hingga menimbulkan } \\
\text { masalah-masalah baru, misal ketidak } \\
\text { nyamanan cara bekerja yang dirasakan oleh } \\
\text { masing-masing pekerja }\end{array}$ \\
\hline 8. & $\begin{array}{l}\text { Weight } \\
\text { Compensation }\end{array}$ & $\begin{array}{l}\text { Mengurangi kompensasi yang berat yang } \\
\text { dirasakan karyawan pada saat melakukan } \\
\text { kesalahan membuat ketidak nyamanan } \\
\text { karyawan }\end{array}$ \\
\hline 9. & $\begin{array}{l}\text { Preliminari } \\
\text { counteraction }\end{array}$ & $\begin{array}{l}\text { Adanya permasalahan yang dialami karyawan } \\
\text { namun tidak langsung disampaikan namun } \\
\text { malah melakukan penyangkalan awal }\end{array}$ \\
\hline 10. & Preliminary Action & $\begin{array}{l}\text { Mengingatkan karyawan yang sulit untuk } \\
\text { melakukan tindakan awal saat menyadari } \\
\text { adanya permasalan }\end{array}$ \\
\hline 11. & $\begin{array}{l}\text { Beforehand } \\
\text { Compensation }\end{array}$ & $\begin{array}{l}\text { Menyiapkan kondisi peralatan maupun } \\
\text { karyawan terlebih dahulu }\end{array}$ \\
\hline 12. & Equipotentially & $\begin{array}{l}\text { Membatasi pergerakan karyawan dengan } \\
\text { memberikan SOP yang baik dan muah } \\
\text { dipahami }\end{array}$ \\
\hline 13. & $\begin{array}{l}\text { "The other way } \\
\text { around" }\end{array}$ & $\begin{array}{l}\text { Melakukan inspeksi serta melakukan } \\
\text { perbaikan }\end{array}$ \\
\hline 14. & Curvature Increase & $\begin{array}{l}\text { Menyesuaikan equipment yang cocok untuk } \\
\text { lokasi indoor dan outdoor }\end{array}$ \\
\hline 15. & Dynamics part & $\begin{array}{l}\text { Memepersiapkan equipment dan lingkungkan } \\
\text { kerja sebaik mungkin agar mencapai kondisi } \\
\text { pengoprasian yang optimal }\end{array}$ \\
\hline 16. & $\begin{array}{l}\text { Partialor exessive } \\
\text { action }\end{array}$ & $\begin{array}{l}\text { Melakukan perbaikan equipment secara } \\
\text { bertahap }\end{array}$ \\
\hline 17. & $\begin{array}{l}\text { Dimensionality } \\
\text { change }\end{array}$ & Memaksimalkan kualitas pelayanan \\
\hline 18. & $\begin{array}{l}\text { Mechanical } \\
\text { vibbration }\end{array}$ & $\begin{array}{l}\text { Meningkatkan kinerja pelayanan baik } \\
\text { equipment maupun karyawan }\end{array}$ \\
\hline 19. & Periodic Action & $\begin{array}{l}\text { Melakukan tindakan diwaktu tertentu seperti } \\
\text { melakukan tindakan saat terjadi masalah }\end{array}$ \\
\hline 20. & $\begin{array}{l}\text { Continuity of useful } \\
\text { action }\end{array}$ & Melanjutkan tindakan yang bermanfaat \\
\hline
\end{tabular}

\begin{tabular}{|c|c|c|}
\hline No & Daftar & Keterangan \\
\hline 21. & Hurrying & Memaksimalkan pekerjaan dengan baik \\
\hline 22. & $\begin{array}{l}\text { 'Blessing in } \\
\text { disguise" }\end{array}$ & $\begin{array}{l}\text { Menggunakan faktor ataupun cara yang } \\
\text { berbahaya untuk melakukan perbaikan }\end{array}$ \\
\hline 23. & Feedback & $\begin{array}{l}\text { Melakukan umpan balik untuk } \\
\text { meningkatkan pelayanan }\end{array}$ \\
\hline 24. & Intermediary & $\begin{array}{l}\text { Mengganti equipment yang tidak tersistem } \\
\text { dengan equipment yang tersistem agar } \\
\text { mudah dalam melakukan persiapan }\end{array}$ \\
\hline 25. & Self-servise & $\begin{array}{l}\text { Menggunakan equipment yang memiliki } \\
\text { performansi yang baik }\end{array}$ \\
\hline 26. & Copying & $\begin{array}{l}\text { Melakukan pengulangan pada sistem yang } \\
\text { sudah baik }\end{array}$ \\
\hline 27. & $\begin{array}{l}\text { Cheap } \\
\text { disposible }\end{array}$ & $\begin{array}{l}\text { Menggunakan objek yang memiliki fungsi } \\
\text { yang sama tapi memilki harga yg lebih } \\
\text { murah }\end{array}$ \\
\hline 28. & $\begin{array}{l}\text { Mechanical } \\
\text { interaction } \\
\text { substitutional }\end{array}$ & $\begin{array}{l}\text { Mengubah cara kerja karyawan yang } \\
\text { sejauh ini tidak maksimal. }\end{array}$ \\
\hline 29. & $\begin{array}{l}\text { Pneumatics and } \\
\text { hydraulics }\end{array}$ & $\begin{array}{l}\text { Melakukan kegiatan pembersihan secara } \\
\text { rutin pada equipment untuk meningkatkan } \\
\text { kualitas }\end{array}$ \\
\hline 30. & $\begin{array}{l}\text { Flexible shells } \\
\text { and thin films }\end{array}$ & $\begin{array}{l}\text { Menggunakan peralatan pelindung } \\
\text { pengaman atau sperpart yang cukup } \\
\text { bagus }\end{array}$ \\
\hline 31. & $\begin{array}{l}\text { Porous } \\
\text { materials }\end{array}$ & $\begin{array}{l}\text { equipment tidak memiliki pelindung alas } \\
\text { bawah sehingga bila memberi pelayanan } \\
\text { di tempat indoor dan becek, equipment } \\
\text { bisa berkarat sehingga perlunya diberi alas }\end{array}$ \\
\hline 32. & $\begin{array}{l}\text { Optical } \\
\text { propperty } \\
\text { changes }\end{array}$ & $\begin{array}{l}\text { Menutupi sound perubahan penampilan } \\
\text { karena efect depresiasi tidak terlihat }\end{array}$ \\
\hline 33. & Homogeneiti & $\begin{array}{l}\text { Membuat objek barinteraksi dengan objek } \\
\text { yang memilki material yang sama }\end{array}$ \\
\hline 34. & $\begin{array}{l}\text { Discarding and } \\
\text { recovering }\end{array}$ & $\begin{array}{l}\text { Menggantikan objek yang sudah tidak } \\
\text { berfungsi dengan objek yang memilki } \\
\text { fungsi yang sama }\end{array}$ \\
\hline 35. & $\begin{array}{l}\text { Parameter } \\
\text { changing }\end{array}$ & Melakukan perubahan parameter \\
\hline 36. & $\begin{array}{l}\text { Phase } \\
\text { trantition }\end{array}$ & $\begin{array}{l}\text { Memanfaatkan box equipment lama yang } \\
\text { sudah tua kemudian diberikan sparpart } \\
\text { yang baru }\end{array}$ \\
\hline 37. & $\begin{array}{l}\text { Thermal } \\
\text { Expansion }\end{array}$ & $\begin{array}{l}\text { Pemanfaatan kemampuan benda dalam } \\
\text { mengurangi suhu panas }\end{array}$ \\
\hline 38. & Strong oxidant & $\begin{array}{l}\text { Lokasi event sangat terbuka sehingga } \\
\text { equipment rentan terkena panas matahari } \\
\text { dan hujan secara langsug }\end{array}$ \\
\hline 39. & $\begin{array}{l}\text { Inter } \\
\text { atmosphere }\end{array}$ & $\begin{array}{l}\text { Penyimpanan produk dilakukan di } \\
\text { ruangan yang tertutup }\end{array}$ \\
\hline 40. & $\begin{array}{l}\text { Composite } \\
\text { materials }\end{array}$ & $\begin{array}{l}\text { Penggunaan bahan komposite untuk untuk } \\
\text { meningkatkan ketahanan equipment } \\
\text { seperti silicon dan sejenisnya }\end{array}$ \\
\hline
\end{tabular}


Design

Tabel 9. Harga Sewa Sound System Problem Solving

\begin{tabular}{|c|c|c|c|c|c|}
\hline \multirow{2}{*}{ No. } & \multirow{2}{*}{ Parameter } & \multicolumn{4}{|c|}{40 Inventing Problem Solving } \\
\hline & & $1-10$ & $11-20$ & $21-30$ & $31-40$ \\
\hline 1. & $\begin{array}{l}\text { Penentuan harga jual } \\
\text { - Tidak mampu memberi gaji tetap pada karyawan }\end{array}$ & $1-3,8$ & & 27 & \\
\hline 2. & $\begin{array}{l}\text { Harga jual yang tidak pasti } \\
\text { - Sulit mengatur keluar masuk cost }\end{array}$ & $1-3$ & & 27 & \\
\hline \multirow{2}{*}{3.} & $\begin{array}{l}\text { Suara yang sangat tajam di telinga } \\
\text { - Karakter sound produk Asia }\end{array}$ & 6,9 & $14,17,18$ & 24,25 & \\
\hline & $\begin{array}{l}\text { - Kurangnya kedekatan dengan client, karena baru pertama kali } \\
\text { menggunakan jasa }\end{array}$ & 2 & 17,18 & $\begin{array}{l}21,23 \\
26,28\end{array}$ & \\
\hline \multirow[t]{2}{*}{4.} & $\begin{array}{l}\text { Merk sound belum memiliki branch image yang baik } \\
\text { - Tidak memiliki kemampuan membaca keinginan client }\end{array}$ & & & 28 & \\
\hline & - Sound system yang merupakan sound merk cina & 5 & & 24,25 & \\
\hline 5. & $\begin{array}{l}\text { Tidak mampunya karyawan memperbaiki equipment yang rusak } \\
\text { - Kurangnya pengetahuan tentang elektronika dari karyawan }\end{array}$ & 9 & 12,13 & & $\begin{array}{c}33,34, \\
36\end{array}$ \\
\hline 6. & $\begin{array}{l}\text { Membuat equipment rusak } \\
\text { - Kurangnya pengetahuan tentang listrik dari karyawan }\end{array}$ & 22 & & & \\
\hline 7. & $\begin{array}{l}\text { Merk sound system yang tidak sama } \\
\text { - Suara yang dihasilkan disetiap sudut berbeda, Pembelian/ } \\
\text { pengadaan barang yang tidak bersamaan }\end{array}$ & 5 & 14,16 & 25 & \\
\hline 8. & $\begin{array}{l}\text { Cara komunikasi karyawan yang kurang baik dengan client } \\
\text { - Karyawan tidak memiliki rasa empati }\end{array}$ & & $11-13,18$ & 23,28 & \\
\hline 9. & $\begin{array}{l}\text { Penampilan karyawan yang kurang rapi } \\
\text { - Kesiapan karyawan dalam bekerja }\end{array}$ & & 11 & & \\
\hline 10. & $\begin{array}{l}\text { Terlambat dalam persiapan barang } \\
\text { - Kecepatan loading barang yang tidak bisa dipastikan }\end{array}$ & & $11,15,18$ & & \\
\hline
\end{tabular}

\section{Dengan cara menjabarkan} rancangan proses dengan mendetail untuk memenuhi kebutuhan pelanggan, dengan memberikan usulan perbaikan tentang masalah yang dihadapi, tahap ini menggunakan metode kontradiksi matriks yang digunakan untuk menggabungkan parameter dengan inventif principle sehingga dapat diperoleh solusi pada setiap parameter. Pada Tabel 9 Inventive problem solving yang muncul $1,2,3,5,6,8,9,10,11$, $12,13,17,18,21,23,24,25,26,27,28,33$, 34,36 . Sedangkan untuk secondary Inventive problem solving yang muncul $5,11,12,13,14$, $16,18,23,25,26,28$. Menurut savransky, penyusunan yang dilakukan berdasarkan pada Inventive Principle adalah yang terjadi minimal satu kali.

\section{PENUTUP}

Kesimpulan dari penelitian yang telah dilakukan adalah:

1. Terdapat beberapa reject service yang mempengaruhi tingkat kepuasan pelanggan, reject service ini didapatakan dari beberapa metode yang digunakan pareto, FTA, FMEA, dan TRIZ mengatakan hal yang sama, dan yang berpengaruh antara lain yaitu: merk sound system yang tidak sama atau tidak seseri, cara komunikasi karyawan yang kurang baik dengan client, sound system tidak menyala maksismal sesuai yang diahrapkan, penampilan karyawan yang kurang rapi, terjadi kerusakan ditengahtengah acara dan tidak mampu tertangani, terlambat dalam persiapan barang, suara yang sangat tajam ditelinga, harga sewa yang tidak selalu pasti, merk sound belum memiliki brand image yang baik.

2. Terdapat 2 reject service yang paling dominan yang harus di perbaiki oleh UD. Cakra Music, yaitu harga sewa sound system dan cara kerja karyawan. Solusi yang harus dilakukan oleh perusahan UD. Cakra Music untuk mengatasi reject service yang paling dominan adalah dengan cara membuat harga paten dalam melakukan penjualan agar mudah mengatur keluar masuk biaya dan memberikan pelatihan pada karyawan tentang cara bersikap yang baik pada konsumen. 


\section{DAFTAR PUSTAKA}

Aji, E. R., \& Yuliawati, E. (2016). Pengembangan Produk Lampu Meja Belajar dengan Metode Kano dan Quality Function Deployment (QFD). Journal of Research and Technology, 2(2), 78-86.

Anggraeni, M., Desrianty, A., \& Yuniar, Y. (2013). Rancangan Meja Dapur Multifungsi Menggunakan Quality Function Deployment (QFD). Reka Integra, 1(2).

Batan Londen, I. (n.d.). Made, 2012. Edisi Pertama, "Desain Produk", Guna Widya, Surabaya.

Chrisdiyanto, B. (2014). Perancangan Dan Pengembangan Meja Belajar Lipat Multifungsi Yang Ergonomis Menggunakan Metode QFD (Quality Function Deployment). Universitas Muhammadiyah Surakarta.

Cohen, L. (1995). Quality Function Deployment - How to Make QFD Work for You. Addison-Wesley Publishing Company, Reading, Massachusetts.

Feri, S., \& Dominikus, J. (2010). Data Mining Meramalkan Bisnis Perusahaan. Elex Media Komputindo. Jakarta.

Jaelani, E. (2012). Perencanaan dan pengembangan produk dengan quality function deployment (QFD). Jurnal Sains \& Manajemen Akuntansi, 4.

Kuswidiyanto, T. (2010). Perancangan Produk Mesin Tetas Telur Tepat Guna sebagai Upaya Peningkatan
Produktivitas Ternak Unggas dengan

Metode Quality Function Deployment. Universitas Dian Nuswantoro, Semarang.

Poedjioetami, E., \& Prabowo, R. (2015). Desain Quality Function Deployment untuk Pengembangan Produk Batik Tulis di Pacitan.

Prabowo, R. (2012). Strategi Peningkatan Kualitas Produk dengan Metode Quality Function Deployment di PT. Karya Teknik Persada Surabaya. Prosiding Seminar Nasional Teknik Industri Waluyo Jatmiko $V$ Universitas Pembangunan Nasional "Veteran" Jatim. ISBN : 978-979-99117-3-5, 3 Juli 2012. Surabaya.

Prabowo, R., \& Purwanto, B. (2016). New Product Development for Dryer Fish for SMEs Scale with Quality Function Deployment (QFD) Method. In Prosiding International Conference ICOEN (Vol. 3).

Saptadi, A. H., Arifin, J., \& Nugraha, W. D. (2010). Perancangan Dan Pembuatan Charger Handphone Portable Menggunakan Sistem Penggerak Generator AC Dengan Penyearah. Jurnal Infotel, 2(2), 12-24.

Trisna; Syamsul Ma'arif, dan Y. A. (2012). Strategi Pengembangan Produk Susu Kedelai Dengan Penentuan Karakteristik Produk. Jurnal Teknik Industri ISSN:1411-6340 157. Universitas Trisakti. Jakarta. 